\title{
The Pharmaceutical Medicine Year that Was, 2012
}

\author{
Anthony W. Fox
}

Published online: 22 January 2013

(C) Springer International Publishing Switzerland 2013

Usually written in October [1], this year's round-up is a little later than usual, covering events from about November 2011 to December 2012. A lot of the regulatory fun took place during the first half of this period.

Remarkably, the US FDA has approved the first cord blood product [2]. The formulation is somewhat unique in that it comprises haematopoietic progenitor cells, for use in patients with haematological, malignant diseases. The Agency had issued a guidance on the subject in 2009, requiring manufacturers of such therapies to file either a licence application or an investigational new drug application for such products [3]. It is to the Agency's credit that it has found a way to review and approve such a modern and different product.

New FDA guidances have been a mixed bag this year. Two useful guidances concerning investigational medical device studies in man appeared at the very beginning of the year. While issued as drafts, these are still the best guidances available on the subject of the conduct of studies when product information is incomplete, and for the testing of prototype devices in feasibility studies. The latter will differ from the device that is going, hopefully, to market $[4,5]$.

FDA progress with guidance about biosimilars has been less than complete, however [6]. The Patient Protection and Affordable Care Act (2010) gave the FDA authority to review and approve biosimilars using different review procedures from those for innovator products. The Agency is taking a different regulatory approach to the well

\footnotetext{
A. W. Fox ( $\square)$

Consulting Editor, Pharmaceutical Medicine

c/o Academic Centre, Room 3.52, Franklin-Wilkins Building,

King's College London, 150 Stamford Street,

London SW10 1LH, UK

e-mail: Tony.Fox@kcl.ac.uk
}

established procedures in Europe [1], in that it is proposing a stepwise review process, with a licensing decision that is then made on the 'totality of the evidence'. The 'steps' in the review are (i) structural and chemical comparability to the innovator; (ii) animal evidence of pharmacodynamics; (iii) toxicity in animals; (iv) comparison of immunogenicity between innovator and biosimilar; and (v) some degree of clinical experience. It is envisaged that the amount of data needed for each of these steps will vary according to the polypeptide in question and that, in particular, the demands for clinical trials will vary according to the uncertainties that may exist among the non-human studies. 'Totality of the evidence' is intended to mean an assessment of whether clinically meaningful differences can be detected between the innovator and biosimilar products within this range of tests. The Agency has offered a few examples of differences that might not be considered clinically meaningful, for example, minor differences in batches of human serum albumin excipients, or minor differences in post-translational modification (e.g. different polypeptide glycosylations) that lack pharmacological impact. As for the clinical evidence, FDA appears to make a distinction between mere biosimilarity (presumably, pharmacodynamic equivalence) and the interchangeability of a biosimilar with an innovator product. Guidance on how to demonstrate interchangeability is expected in 2013.

The other big FDA news of the year was completion of the fifth round of the Prescription Drug User Fee Act (PDUFA V) approval [7]. This was uncontroversial, presumably because of the 2 years of consultations that had been held. The renewed Act covers fiscal years 2013-7. As might be expected, fees are increasing, accompanied by assurances of enhanced review transparency, better communication and 'enhanced benefit-risk assessment in regulatory decision making'. 
Bevacizumab (Avastin ${ }^{\circledR}$; Roche, Genentech) has had a rough year, as predicted in last year's review [1]. In December 2012, it was reported that the National Institute for Health and Clinical Excellence (NICE) rejected bevacizumab for ovarian cancer [8]. This follows previous rejections by NICE for colon cancer and metastatic breast cancer in 2010 and 2011, respectively [9, 10]. The FDA revoked the breast indication in November 2011 (the approval had been accelerated, and two post-approval clinical trials evidently failed to confirm the efficacy findings of the initial pivotal study) [11]. The NICE rejections, however, were not for lack of efficacy, but because of an assessment that the treatment was too costly for the benefit that it delivers. 'Benefit' in oncology is (admittedly as a simplification) assessed by NICE, mostly as a median increase in lifespan in comparison to alternative treatments among clinical trial patients. For the breast cancer indication, this median increase in lifespan was 5 months, and, as far as NICE was concerned, this was not worth the approximate $£ 1700$ per month, after the manufacturer had offered a discount [10]. This is a neat example of the fundamental gap between pharmacoeconomics and medicine: the former (after bureaucratic delay, which saves money per se) leads to blanket negative recommendations based upon costs and median life span extension. Meanwhile, clinicians are expected to treat individuals to the best of their ability and, by definition, half of the patients with the appropriate type of disseminated breast cancer would have derived longer survival benefit than the median value used by NICE. Of course, you never know in advance which patients are going to be the better-thanaverage responders. Meanwhile, NICE is rumoured to be reassessing the cost effectiveness of oseltamivir, while the FDA has extended its indication to children less than 1 year of age, under the extrapolated data provisions of the pediatric regulations [12]. It would appear that, overall, Sir Andrew Dillon's statement: "NICE is committed to ensuring the most effective treatments, both for patients and the NHS, are available to those who need them" [10] needs serious scrutiny.

The Plan $B^{\circledR}$ (Teva Pharmaceutical Industries, Ltd) controversy is still not quite over. This product is designed for over-the-counter (OTC) use as a postcoital contraceptive and, in 2005, was finally approved in the US for women who were at least 17 years of age, amidst much controversy. A Government Accountability Office inquiry subsequently found that the review process used by FDA for this OTC switch was highly unusual; in particular, the review had involved Government officials of much higher rank than for 67 other OTC switches. Moreover, FDA officers had given differing stories to the inquiry about how the review had been conducted [13]. The suspicion was that political interference from within the administration of
George W. Bush had been allowed to overrule the usual assessment processes of the scientific divisions of the FDA. This year's re-eruption was over a licence amendment to allow OTC access of the product to patients under the age of 17 years. Once again, the scientific divisions of FDA recommended approval and, once again, they were overruled by the Health and Human Services Secretary (Kathleen Sibelius). Ms Sibelius is a US Cabinet Minister without a scientific background (she has a bachelor's degree in political science, a master's degree in public administration and was an Insurance Commissioner and Governor of the State of Kansas, USA). Cabinet Ministers ordinarily have nothing to do with new drug application amendments. Politics, once more, seems to have trumped science at the FDA. Inevitably, there was an activists' outcry which, unusually, found a sympathetic ear with Judge Edward Korman (US District Court for Eastern District of New York, USA), who invited The Center for Reproductive Rights to reopen a lawsuit against FDA seeking unrestricted access to the product (it was Korman who had adjudicated the previous refusal for the OTC switch). Meanwhile, questions have been asked in Congress (e.g. by Senator Patty Murray, Democrat-Washington, DC, USA), and the product remains available OTC only to those who can prove to a pharmacist that they are over 17 years of age.

The big European regulatory event of the year was the new pharmacovigilance procedures introduced in July, with the revision of Eudravigilance Volume 9A. The European Medicines Agency (EMA) has established the Pharmacovigilance and Risk Assessment Committee (PRAC; Chair, Dr June Raine). This committee has essentially taken away postmarketing risk management activities from the licensing rapporteurs. There is a new format Periodic Safety Update Review (PSUR); this is no longer the safety update and adverse event listings of old, but must also have a risk-benefit assessment. Kindred products with different marketing authorization holders must now submit synchronized PSURs according to anniversaries of an 'international birthday'. Expedited reporting of non-serious adverse events is also now required, although what the EMA officers are going to do with this mass of data is unknown. Non-medically validated adverse drug reports (e.g. from consumers) must also now be reported. These operational changes have been introduced with the usual mantra that they are supposed to strengthen the pharmacovigilance process, increase the efficiency of the EMA and increase transparency, although it is unclear what the EMA might be measuring to assure that these goals are being achieved

This year, France, too, has been pursuing a supposedly more efficient and transparent regulatory process. There is a new French National Agency of Medicine and Health 
Products; Agence Nationale de Sécurité du Médicament et des Produits de Santé (ANSM). Its predecessor lost Government confidence after withdrawal of benfluorex, and in the context of controversies about breast implants [14]. The Director General (Dr Dominique Maraninchi) is extending conflicts of interest disclosures to much lower echelons of staff than previously, and application fees from industry have evidently been abolished. The Agency has also a discretionary research budget for pharmacovigilance research [14]. Given the laws and unions that control French Government employment, one can only assume that the staff of this new Agency is the same as the old one, although one senior French delegate to the EMA does seem to have been a casualty.

What can we expect next year? The economic situation will still cast a long shadow. Europe wallows in ever more expensive postponements of the definitive economic action that is needed, and the Brussels bureaucrats continue to defy common sense with speeches and statements that are occasionally punctuated by anti-UK gibes for lack of commitment to the 'European ideal'. This is not exactly problem solving behaviour. Constant changes in tax codes and employment policies in Europe, the US and the UK create a general drag on the entire economy because those who invest need some sort of stability before making decisions. Small pharma and biotech companies are two of the casualties as a result. In the US, wrangling over taxes and budget cuts carries on, and the fragile (but recovering) US economy could easily become a casualty of legally mandated reversals of tax cuts and government spending plans as soon as 1 January 2013. On the purely regulatory side, the EMA will also be experimenting with the public disclosure of clinical trials data and, hopefully, the FDA will tell us what it thinks interchangeability of biosimilars might be. Meanwhile, strangely, NICE will be championing local formularies because it thinks it will reduce variation in prescribing [15]!

Happy New Year.

\section{References}

1. Fox AW. The pharmaceutical year that was, 2011. Pharm Med. 2012;26(1):1-3.
2. US Food and Drug Administration. FDA approves first cord blood product [media release] 2011 Nov 10 [online]. http://www.fda. gov/NewsEvents/Newsroom/PressAnnouncements/ucm 279525. htm. Accessed 5 Dec 2011.

3. US Food and Drug Administration. Guidance for industry: minimally manipulated, unrelated allogenic placental/umbilical cord blood intended for hematopoietic reconstitution for specified indications. Washington, DC: FDA; 2009.

4. US Food and Drug Administration. Draft guidance for industry: FDA decisions for investigational device exemption (IDE) clinical investigations. Washington, DC: FDA; 2011.

5. US Food and Drug Administration. Draft guidance for industry: investigational device exemptions (IDE) for early feasibility medical device clinical studies, including first in human (FIH) studies. Washington, DC: FDA; 2011.

6. US Food and Drug Administration. Guidance for industry: scientific considerations in demonstrating biosimilarity to a reference product. Washington, DC: FDA; 2012.

7. US Food and Drug Administration. FDA Safety and Innovation Act, 2012, signed by the President 2012 Jul 9 [online]. http:// www.fda.gov/ForInductry/UserFees/PrescriptionDrugUserFee/ucm 272170.htm. Accessed 24 Dec 2012.

8. Wickham C, Potter M. NICE may reject Roche's Avastin for ovarian cancer [online]. http://uk.reuters.com/article/2012/12/18/ uk-roche-cancer-avastin-idUKBRE8BH00K2012. Accessed 21 Dec 2012.

9. Pidd H. Avastin prolongs life but drug is too expensive for NHS patients, says NICE. The Guardian [media release]. 2010 Aug 23 [online]. http://www.guardian.co.uk/society/2010/aug/24/avastintoo-expensive-for-patients. Accessed 21 Dec 2012.

10. NICE. Avastin (bevacizumab) is not recommended for the treatment of metastatic breast cancer in new guidance from NICE [media release] 2011 Feb 23 [online]. http://www.nice.org.uk/ newsroom/pressreleases/AvastinBevacizumabnotrecommended. Accessed 21 Dec 2012.

11. FDA. FDA Commissioner removes breast cancer indication from Avastin label [media release] 2011 Nov 18 [online]. http://www. fda.gov/NewsEvents/Newsroom/PressAnnouncements/ucm279485. htm. Accessed 21 Dec 2012.

12. FDA. FDA expands Tamiflu's use to treat children younger than 1 year [media release]. 2012 Dec 21 [online]. http://www.fda. gov/NewsEvents/Newsroom/PressAnnouncements/ucm333205. htm. Accessed 24 Dec 2012.

13. United States Government Accountability Office (GAO). Report to Congressional Requesters: Food and Drug Administration decision process to deny initial applications for over-the-counter marketing of emergency contraceptive drug Plan B was unusual. Washington, DC: GAO; 2005.

14. Lochouarn M. France launches new drug regulatory agency. Lancet. 2012;379:2136.

15. NICE. NICE local formularies guide will 'reduce variation in prescribing' [media release]. $2012 \mathrm{Dec} 17$ [online]. http://www. nice.org.uk/newsroom/news/NICELocalFormulariesGuideWill ReduceVariationinPrescribing. Accessed 24 Dec 2012. 